\title{
OBSERVATIONS OF THE MERLIN FROM UNITY, SASKATCHEWAN
}

\section{ALLEN G. YOUNG, P.O. Box 873, Unity, Saskatchewan, SOK 4 LO.}

Ever since my early years of birding in south-central Saskatchewan, I have had a keen interest in all birds of prey. Just recently I spent considerable time with the smallest members of the falcon family, the Merlin and American Kestrel. This article pertains to the Merlin.

I have been extensively observing the Merlin in the Unity district for the past three years. My records are all backed up in writing, as well as prints and slides. Most of my work takes place from the last week of April, before the trees leaf out, until the first week of September. Most of my photography takes place early in the summer. My main interests are the number of Merlins in west-central Saskatchewan and their feeding habits. I have found the breeding population in the Unity-Vera area to be quite high, with a density of approximately one pair of birds per $8 \mathrm{~km}^{2}$.

Although the female bird is quite a bit larger and a lot more aggressive, the mated pair are very close and fights over food seldom result. Most of my information on habits comes from long observations in tree blinds. Altogether, my records total approximately 80 sightings in locations such as Unity, Unity Gas Flats, Vera, Reward, Salvador, Winter, and Artland, Sask., as well as Chauvin, Alberta. The information below is for two nests: one located $5 \mathrm{~km}$ south and $2 \mathrm{~km}$ west of Unity - it overlooks the natural gas reserves; the second nest is $5 \mathrm{~km}$ north and $5 \mathrm{~km}$ west of Unity in the Vera Community Pasture.

\section{Nest 1, Unity Gas Flats}

Time spent observing -20 hours, of which about 16 hours were in a blind 8 feet from the nest.

This area is totally devoid of trees, except in spring-fed ravines and north-facing slopes. The nest was located 10 feet from the ground in a stunted aspen poplar. The entire bluff was about 100 yards long and 30 yards wide, with the stunted trees bound to the sharp slope. The bluff overlooks a 7 -mile-long valley (glacial outwash), several hundred feet deep with the gas fields of End Lake at the base.

I first located the nest on 20 April 1978. The ground was still covered with snow. The Merlins were seen circling about a mile away and their continuous cries gave away its location. They had used a magpie nest. The old outer lining of mud was still intact and no additional material was added for a lining. The nest eventually contained 7 eggs, Bent indicates that even six is a rare occurrence. ${ }^{1}$ Of five trips to the nest in the morning during incubation, the male was always incubating and the whereabouts of the female was unknown.

The nest was first photographed in the last week of May, when the young were in the process of hatching. Only one bird was totally out of the shell, two other eggs were cracked around. I helped the second bird out and took pictures. It is important to note that on the day of hatching one adult sparrow 
p. (plucked), was among the eggs and hatchling. The plucking log was ocated about 16 yards from the nest with the ground beneath strewn with he feathers of various sparrows, ther song birds, shorebirds and even he feathers of a Black-billed Magpie.

I set up a blind about 2 weeks later and spent several hours each day bserving and taking pictures. The emale was quite concerned at first out gradually learned to live with the lind. The only prey ever identified at he nest was Clay-colored Sparrow. The prey was nearly always brought o the nest totally plucked. The young alcons were always excited and vould almost always pile up against he female, pushing her off the edge of the nest. She, never the male, took sare of feeding even though the oung were quite large. The male was he provider, exchanging the prey vith the female away from the nest ite. Whenever the male appeared in he northern skies, the female ecame very excited, which seemed 0 rub off on the young birds.

My last observation of this nest was ate in July. All six young birds fledged and were noted on several later outngs with the adult birds. They stayed $n$ the valley area until late fall. The imnature birds were very curious, lways diving at each other and ocasionally coming to within hitting ange of myself. This close family rouping seems to be characteristic of the species. I observed several ther playful family groupings during August while working on the C.N. rack in the Manitou Forest Reserve.

\section{Nest 2, South SIde of Akerlund Lake n Vera Community Pasture}

Time spent observing -10 hours 1978.

This area was $70 \%$ covered with tunted trees, including aspen poplar and willow as well as sagebrush. The

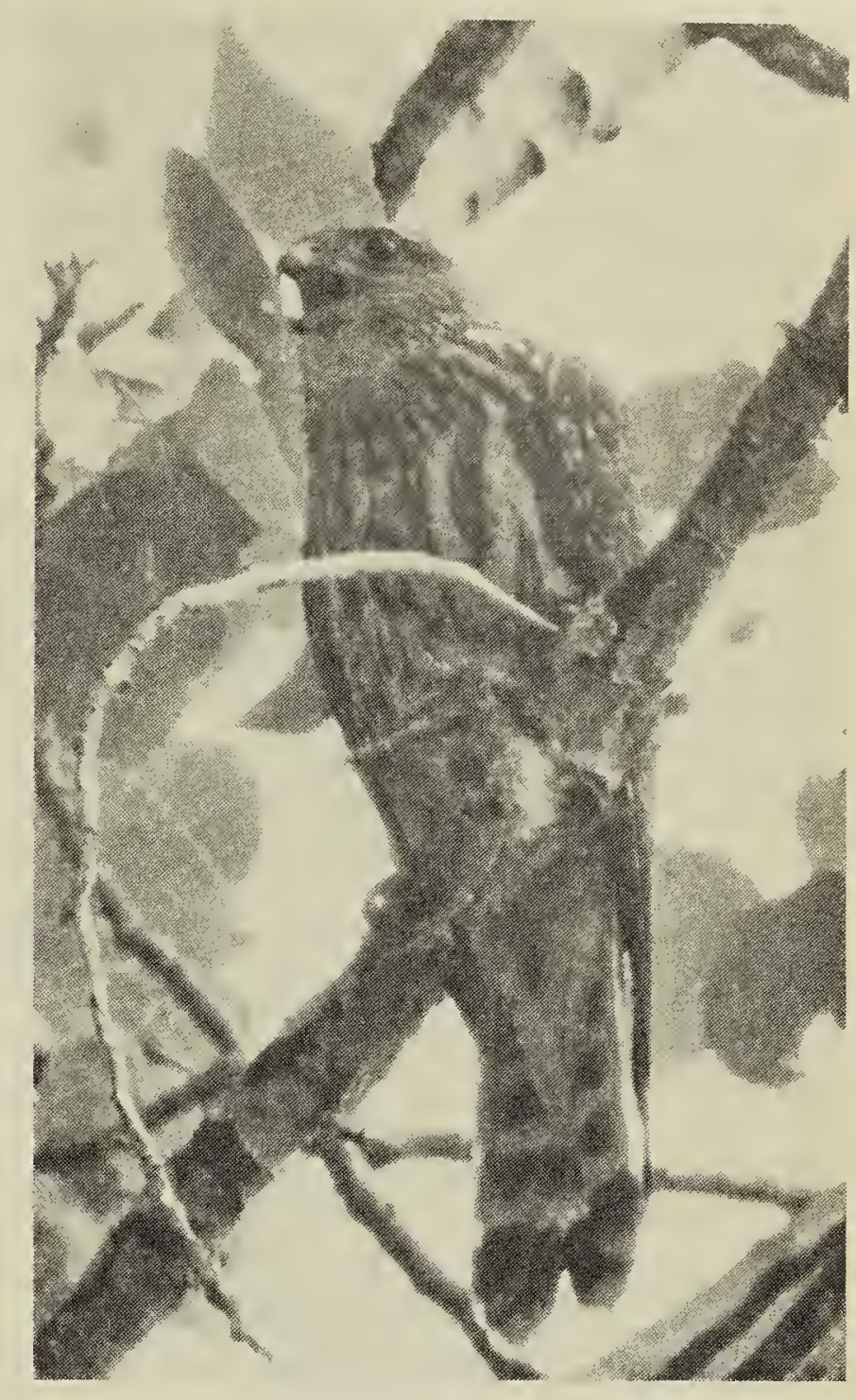

Adult female Merlin with House Sparrow. Lynn Oliphant

nest was located when the five young were already fledged. It is interesting to note that nearby, within 300 yards, was the nest of a Cooper's Hawk with three young. Also, within one $\mathrm{km}$ were two Red-tailed Hawk nests.

I have no data on incubation or egg coloration, but the adult birds were about the same as those of nest number one. This nest was also an old magpie's, about 12 feet from the ground in an aspen and willow thicket about half a kilometre square. Again the nest was unlined. The young seemed to be healthy and well fed by both parents. The food included many types of song birds. Hunting always included direct pursuit with the advantage of height, always in the open and never in the thorny undergrowth. The falcons had far superior speed in level or rising flight, but 
sometimes lacked the precision of movement to capture species such as the Eastern Kingbird.

The stoop is far superior to that of the Kestrel. I have been dived on repeatedly but only by the female and only while approaching the nest from open terrain. While in close proximity to the nest, the parent birds usually circle or perch within 40 feet.

'BENT, A. C. 1938. Life histories of North American birds of prey. Part II. Smithsonian Inst. U.S. Nat. Mus. Bull. 170. (1961 Dover Edition).

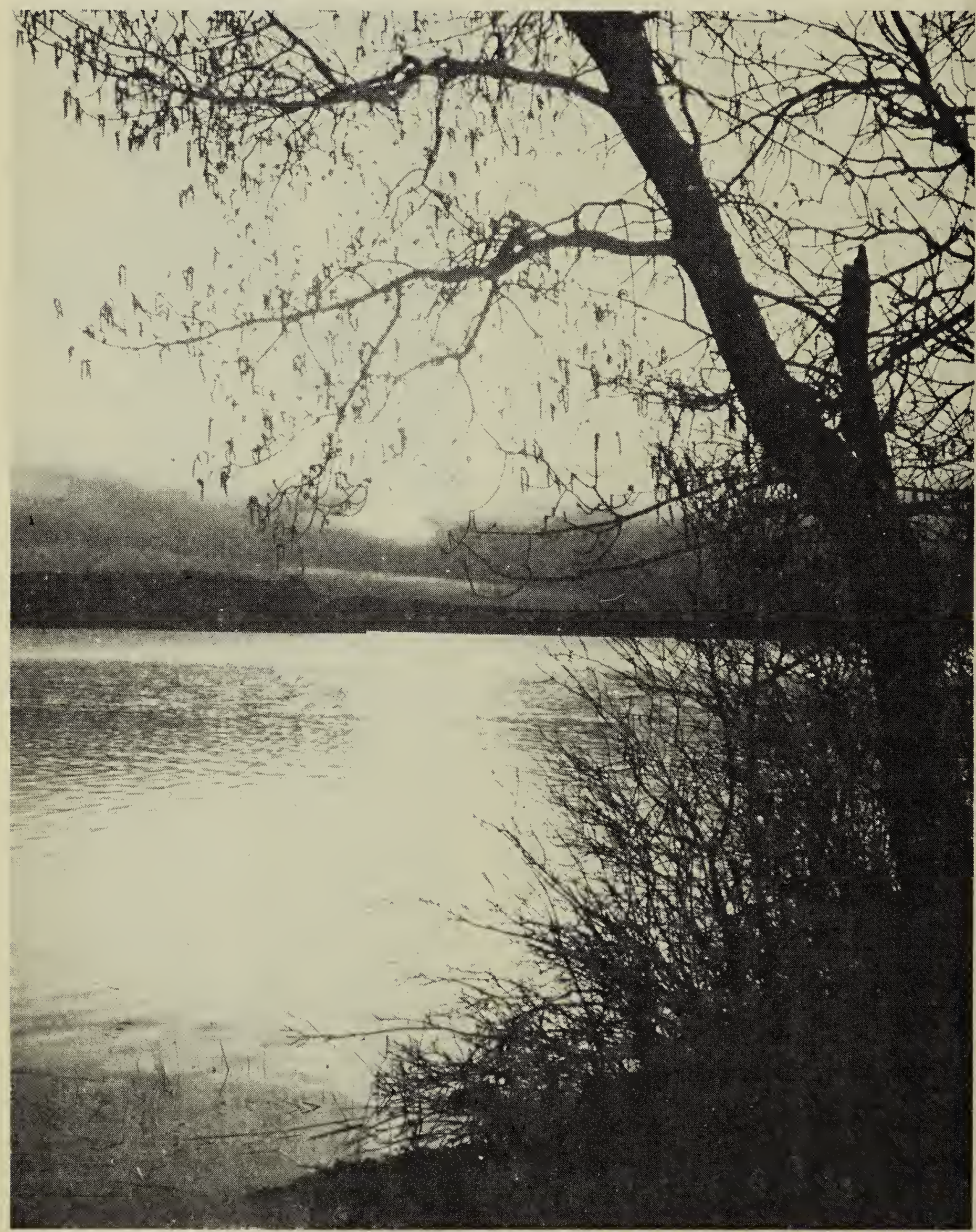

